\title{
As Limitações dos Sistemas de Metas
}

\author{
Mário Teixeira Reis Neto ${ }^{1}$ \\ João Henrique Soares do Couto ${ }^{2}$ \\ Carlos Alberto Gonçalves ${ }^{3}$
}

\section{Resumo}

Neste ambiente de grandes incertezas em que as organizações estão inseridas, a correta utilização de um sistema de medição pode significar vantagem competitiva e desempenho. Este ensaio procura esclarecer os limites dos sistemas de medição, verificando se a utilização de metas de resultado é suficiente para que uma empresa tenha um desempenho superior. O objetivo é analisar a teoria das metas sob um olhar crítico, observando os limites da utilização de diversos tipos de metas, até mesmo no serviço público. Buscou-se fazer uma análise das pesquisas dos autores que defendem a utilização de metas para se ter desempenho e, a partir das suas premissas, analisar os estudos dos autores que as criticam, mostrando que elas podem causar, dependendo da situação, sérios danos financeiros e à imagem da organização. Após essa análise, verificou-se que as metas possuem um importante papel no aumento do desempenho da organização, todavia, deve-se ter certo cuidado na sua utilização, pois elas podem levar as pessoas a comportamentos não éticos, à inibição da cooperação e do aprendizado organizacional, entre outros.

Palavras-chave: Metas. Teoria das metas. Limites da teoria das metas. Sistemas de medição.

\section{Introdução}

As organizações estão inseridas em um ambiente institucional de grandes incertezas, fruto das mudanças ocorridas na nova economia, como o

\footnotetext{
${ }^{1}$ Doutor em Administração pela Universidade Federal de Minas Gerais - UFMG. Professor do Programa de Mestrado em Administração do Centro Universitário UNA. End.: Rua Guajajaras 175 - 1ª andar - Centro - Belo Horizonte - MG. CEP: 30180100 - Brasil. E-mail: mario.reis@prointernet.com.br.

${ }^{2}$ Mestrando em Administração pela Universidade Fumec. End.: Av. Afonso Pena n ${ }^{\circ} 3880$ - $1^{\circ}$ andar - Cruzeiro, Belo Horizonte - MG. CEP: 30310009 -Brasil.E-mail: jhcouto@hotmail.com.

${ }^{3}$ Doutor em Administração pela Universidade de São Paulo - USP. Professor do Programa de Mestrado e Doutorado da Universidade Fumec. End.: Av. Afonso Pena n ${ }^{\circ} 3880$ - $1^{\circ}$ andar - Cruzeiro, Belo Horizonte - MG. CEP: 30310009 -Brasil. E-mail: carlos@face.ufmg.br.

Artigo recebido em: 03/04/2010. Aceito em: 07/12/2010. Membro do Corpo Editorial Científico responsável pelo processo editorial: Rolando Juan Soliz Estrada.

(c) (i) (-) Esta obra está sob a Licença Creative Commons Atribuição-Uso.
} 
advento de novas tecnologias da informação (ZANINI; LUSK; WOLFF, 2009). Segundo Zanini, Lusk e Wolff (2009), a incerteza ambiental, na forma da ausência de informações, afeta consideravelmente o comportamento humano nas organizações, restringindo o desenvolvimento de confiança, devido ao consequente aumento da incerteza comportamental. Nota-se, então, que essa incerteza não é algo desejável para as organizações, considerando que ela restringe o desenvolvimento de confiança interna.

Nesta nova realidade, em que a incerteza se caracteriza como um fator preponderante, Locke e Latham (1990; 2006) constataram que o processo de medição e aferição de metas se torna muito importante para dar uma direção para as empresas e, assim, obter melhores resultados. Os autores também observam que os executivos compreendem a grande importância de se medir o desempenho da empresa e de se aferir metas.

Um sistema de metas, todavia, deve estar alinhado com as estratégias da empresa. A formulação da estratégia, considerando seu aspecto clássico formal, baseia-se na ideia de escolher uma entre as várias alternativas de rumos da organização e seguir o rumo escolhido por um determinado tempo. O objetivo geral é sempre adquirir competitividade estratégica e obter resultados superiores, considerando que a empresa tenha como intenção perpetuar no tempo. Nesse sentido, a empresa deve definir sua missão, visão, princípios organizacionais, objetivos e indicadores estratégicos (HITT; IRELAND; HOSKISSON, 2008; KAPLAN; NORTON, 1997).

Após a formulação da estratégia, o próximo passo é a sua implementação. Essa etapa consiste nas ações estratégicas e nos controles organizacionais, realizados principalmente por meio de um sistema de metas (SIMON, 2000). Hitt, Ireland e Hoskisson (2008) concordam com Simon (2000) e observam que, para a implementação da estratégia, necessita-se também de um bom sistema de governança corporativa, além de um bom sistema de controles internos e de uma estrutura organizacional adequada.

Os controles organizacionais, por sua vez, guiam a implementação da estratégia, mostram como comparar os resultados obtidos em relação aos planejados e direcionam ações corretivas a serem realizadas quando a diferença entre esses últimos é inaceitável. Os controles são baseados em um sistema de metas a serem cumpridas de acordo com a estratégia da empresa.

Segundo Kaplan e Norton (1997), um sistema de medição pode se tornar um fator de vantagem competitiva em um ambiente de incertezas, pois ele tem como premissa melhorar o desempenho da organização. Para os au- 
tores, um sistema de metas pode ser definido como a forma com que uma organização mede as variáveis julgadas importantes para o seu negócio.

Considerando essas premissas, um sistema de metas eficiente e eficaz faz-se necessário em todas as organizações, pois é o caminho para um desempenho superior. Por outro lado, Ordóñez et al. (2009) afirmam que existem alguns caminhos para o alcance de metas que não são ideais, pois não levam a um aumento do desempenho e podem trazer prejuízos para a organização. Esses caminhos podem ser considerados como limitações no uso de metas. Assim, este artigo tem como objetivo apresentar limites dos sistemas de metas e registrar os motivos que os levam a não cumprir com o objetivo de elevar os resultados de todas as organizações.

\section{A Teoria das Metas}

Locke e Latham (1990; 2006) desenvolveram uma teoria sobre metas, na qual verificaram como um sistema de medição e aferição de metas pode melhorar o desempenho de uma organização. Eles observaram que uma meta de desempenho estimula a motivação, a persistência e dá uma direção ao trabalho dos empregados de uma organização. Todavia, essa meta deve ser definida segundo três vertentes: ela deve ser desafiadora, específica e atingível (TOSI, 1991).

Apesar das contribuições de diversos autores, os pontos-chave da teoria das metas mantiveram-se nas três vertentes citadas por Locke e Latham (1990; 2006). A primeira diz que as metas devem ser desafiadoras. As metas desafiadoras, todavia, são preferíveis às metas de fácil alcance, pois elas não são tão eficazes na motivação de pessoas. Assim, as metas de fácil alcance não levam as organizações aos mesmos patamares que as metas desafiadoras (LOCKE; LATHAM, 1990; 2006; TOSI, 1991).

Outro ponto-chave da teoria das metas diz respeito à especificidade da meta. Conforme a teoria apresentada por Locke e Latham (1990; 2006), essa vertente dá uma direção às pessoas, permitindo que elas tenham clareza do seu foco. As metas específicas são um guia para o empregado, mostrando o caminho a ser seguido.

A última questão dessa teoria refere-se à capacidade de alcance da meta. Essa vertente preconiza que metas que não são atingíveis desmotivam as pessoas, pois, independente do esforço que se fizer para o seu cumprimento, 
elas não serão atingidas. Quando se visualiza uma meta possível de se atingir, a pessoa se motiva para tentar alcançá-la, aumentando, assim, sua produtividade e os resultados da organização (LOCKE; LATHAM, 1990; 2006; TOSI, 1991).

Verifica-se que essa teoria baseia-se na ideia de que as metas motivam as pessoas e, consequentemente, levam as organizações a resultados superiores. Seus defensores advogam que a utilização de metas em uma organização gera mais resultados do que simplesmente não tê-las.

Yearta, Maitlis e Briner (1995) observaram que diversas organizações utilizam um sistema de metas com o objetivo de motivar os empregados e, assim, aumentar os resultados das empresas. Tendo em vista tal constatação, eles realizaram uma pesquisa para verificar a relação entre metas definidas por meio de um processo participativo e de desempenho organizacional. Os resultados da pesquisa mostraram que existe uma correlação positiva entre a participação do empregado na definição de metas e a melhora do desempenho, corroborando a ideia de que metas motivam pessoas. Essa mesma pesquisa mostrou outros resultados que serão tratados no item "Limites da teoria das metas".

Deve-se ressaltar que os defensores da teoria das metas argumentam que, na mente dos empregados, o sucesso no alcance de uma determinada meta traz um sentimento positivo, uma recompensa. Essa recompensa não é necessariamente monetária ou tangível, mas uma recompensa interna por aquele feito. Seria como um pedido de um relatório por parte do presidente de uma empresa para um analista, que, ao realizá-lo e entregá-lo ao presidente, mesmo não recebendo uma recompensa financeira por aquele feito, sente-se recompensado internamente (FRIED; SLOWIK, 2004).

Todavia, essa recompensa pode ser monetária e refletir na remuneração do empregado. Saber como remunerar o empregado a partir do cumprimento das metas estipuladas pode, então, afetar a motivação das pessoas. Locke (2004) elenca quatro métodos de se utilizar o sistema de remuneração para o alcance de metas:

a) Tudo ou nada: se o empregado atinge a meta ele recebe a remuneração completa, caso contrário, ele não recebe nada, mesmo estando próximo de atingir a meta.

b) Múltiplos níveis: as metas são fragmentadas em faixas, sendo que cada uma está associada a uma remuneração. 
c) Linear: as metas nesta dimensão são lineares à remuneração, ou seja, o percentual de alcance da meta coincide com o percentual do valor da remuneração.

d) Subjetivo: as metas são estipuladas e a remuneração varia de acordo com o alcance delas, ou não, sendo determinada por uma terceira pessoa, geralmente chefe ou supervisor. Essas pessoa verificará outros fatores que afetam o resultado, como o grau de esforço do empregado, condições externas, e, assim, decidir sobre a remuneração.

Além das três vertentes que se deve observar no momento de definir metas de resultado, Fried e Slowik (2004) acrescentaram o fator tempo. Assim, a meta deve ser desafiadora, específica e atingível e ter um tempo suficiente para a sua realização.

George (2006) afirmo que, no processo de aferição de metas, deve-se observar que as elas sejam:

a) descritas e formalizadas, para não serem esquecidas;

b) alcançáveis, pois metas não alcançáveis geram desmotivação da força de trabalho; $e$

c) mensuráveis, para serem quantificadas e, assim, determinísticas.

Medlin e Green Jr. (2009) realizaram um estudo para verificar se a utilização de metas aumenta o engajamento, o otimismo e o desempenho das pessoas. Os resultados da pesquisa mostraram que as metas impactam de maneira positiva o engajamento, o otimismo e a produtividade das pessoas. Notou-se que, apesar desse estudo corroborar a teoria das metas, ele possui limites de interpretação, pois baseou-se na percepção dos entrevistados e não em dados específicos sobre a produtividade das pessoas.

Boyne e Chen (2007) também realizaram uma pesquisa com organizações públicas de ensino na Inglaterra, visando verificar se a utilização de metas aumentava o desempenho nessas organizações. A pesquisa durou de 1998 a 2003, e os resultados constataram que essa relação era estatisticamente verdadeira, corroborando a teoria das metas.

Chua e Lee (2007) realizaram um estudo de caso mostrando a importância do planejamento das metas de aprendizado para o desenvolvimento de uma organização. Eles mostraram que definir metas personalizadas e co- 
letivas, dentro de um modelo planejado, pode ajudar a organização a aumentar o seu aprendizado, refletindo, assim, no seu desempenho.

Como se pode constatar, muitos estudos comprovaram e complementaram a teoria das metas, entretanto, não se pode pensar que aplicá-la é ter garantia de sucesso nas organizações. Assim, serão apresentadas a seguir algumas de suas limitações que precisam ser compreendidas para não se incorrer em erros que possuem potencial para gerar consequências indesejáveis.

\section{As Limitações dos Sistemas de Metas}

A teoria das metas vem sendo utilizada por diversas empresas em todo o mundo e possui um grande número de defensores. Paralelamente a isso, seu uso ao longo dos anos serviu para evidenciar problemas em situações distintas. Segundo Ordóñez et al. (2009), existe um grande risco para a saúde das empresas, caso o processo de definição de metas de desempenho seja utilizado sem um prévio conhecimento do assunto.

Chu (2004) investigou empresas americanas que utilizavam o sistema de remuneração por alcance de metas para se obter maior desempenho e ele verificou que, em $83 \%$ delas, ou esse sistema não estava funcionando, ou estava funcionando em parte. A pesquisa apontou que havia algum problema com o sistema de metas nas organizações americanas e, possivelmente, nas demais.

Contrapondo-se à ideia de que um sistema de metas sempre levará as organizações a um desempenho superior, alguns autores expuseram críticas distintas à teoria das metas, que serão apresentadas a seguir.

\subsection{Metas Específicas e suas Implicações Negativas}

Usando metas, as organizações focam determinado resultado, o que pode levar a organização a se esquecer de outras variáveis importantes que podem comprometer todo o seu desempenho. A cobrança sobre os empregados no alcance de determinada meta pode levá-los, miopemente, a se esforçarem nos ganhos de curto prazo e a comprometerem perigosamente os resultados de longo prazo das organizações (ORDÓÑEZ et al., 2009). Algumas empresas focam crescimento via aquisições, batem sua meta de partici- 
pação de mercado, porém se esquecem de monitorar o capital organizacional por meio de indicadores e metas relacionados ao clima, ao aprendizado, à padronização de tarefas e ao trabalho em equipe (KAPLAN; NORTON, 2004).

Outro risco é a definição de metas específicas para indicadores que não são os mais apropriados para guiar a organização à maximização do seu resultado. Essa atitude pode levar a Organização a ter sérios problemas econômicos e financeiros. Um exemplo desse caso é o da empresa americana de energia Enron, nos anos de 1990 focou em suas metas somente o aumento de receita, em vez de focar o aumento da lucratividade, o que a levou a um cenário em que as metas foram atingidas, os executivos receberam um bônus pelo alcance desses resultados, mas a organização passou por sérios problemas financeiros (ORDÓÑEZ et al., 2009).

Percebe-se que metas muito específicas podem trazer problemas para a organização, entretanto, conforme Ordóñez et al. (2009) constataram, essa afirmação não quer dizer que toda meta específica trará problemas para a organização.

As metas específicas de desempenho também podem ser uma barreira para a cooperação entre empregados em uma organização, segundo Ordóñez et al. (2009). Eles argumentam que organizações que utilizam metas de desempenho podem fomentar um ambiente de competição interna que bloqueie o fluxo de informações entre as unidades e as pessoas, levando, assim, a empresa a resultados aquém do que poderia obter, se o ambiente fosse mais cooperativo.

Percebe-se que apenas definir uma meta específica pode não ser condição suficiente para se ter uma aumento do desempenho organizacional. A seguir, estão elencados outros fatores que podem limitar o sucesso de um sistema de metas.

\subsection{Os Riscos das Metas Ousadas e Desafiadoras}

Segundo Locke e Latham (1990; 2006) e Tosi (1991), as metas desafiadoras geram uma maior motivação, esforço e comprometimento dos empregados no seu alcance, quando se compara tais resultados com os obtidos quando não se utiliza esse expediente.

Tal constatação não pode ser entendida como uma regra geral, pois existem limites que precisam ser compreendidos quando são utilizadas metas desafiadoras. Por exemplo, Yearta, Maitlis e Briner (1995) pesquisaram a 
relação existente entre as metas definidas por meio de um processo participativo e o desempenho organizacional e a relação entre as metas difíceis, ou desafiadoras, e esse mesmo desempenho. Os resultados da pesquisa mostraram que a correlação é fraca entre as metas desafiadoras e o melhor desempenho empresarial. Percebe-se que a teoria das metas não foi comprovada empiricamente, apesar dos autores reconhecerem os diversos trabalhos que atestam que essa relação é forte, ou seja, metas desafiadoras levam a um maior desempenho.

Segundo Yearta, Maitlis, Briner (1995), o estudo de caso realizado não foi suficiente para desmentir uma teoria que há algumas décadas postula que metas desafiadoras geram maior desempenho, mas ao menos leva a uma reflexão mais crítica sobre o tema.

Quando se utiliza o processo de estabelecimento de metas, deve-se ter uma visão das possíveis consequências de sua aplicação, conforme exposto por Ordóñez et al. (2009). Os autores citam como exemplo a Sears, que, no início dos anos de 1990, estabeleceu uma meta de vendas, para o setor de reparação de automóveis, de U\$147,00 por hora, por veículo. Como consequência, os empregados realizaram reparos desnecessários nos automóveis dos clientes para alcançar a meta estabelecida. O próprio presidente do Conselho de Administração da Sears reconheceu que o estabelecimento daquelas metas levou os empregados a enganarem os clientes, trazendo assim danos à imagem da empresa.

Ordóñez et al. (2009) reconhecem, também, que existe um senso lógico entre metas desafiadoras e melhora do desempenho. Todavia, eles argumentam que definir e cobrar grandes desafios pode gerar sérios efeitos colaterais na organização, como aumento de decisões muito arriscadas, comportamentos não éticos e custos psicológicos, quando os empregados não conseguem atingir a meta estipulada.

O foco excessivo em algumas metas muito desafiadoras pode ter levado os empregados de algumas organizações a comportamentos muito arriscados, sendo essa atitude a razão central de muitos colapsos empresariais verificados nos últimos anos, segundo Ordóñez et al. (2009). Ainda, segundo os autores, um exemplo desse tipo de comportamento muito arriscado devido a metas desafiadoras foi o caso do banco americano Continental Illinois BanK, que, em 1976, era o nono maior banco nos Estados Unidos da América e anunciou uma estratégia de se igualar aos maiores bancos daquele país em cinco anos. Em razão do curto prazo para uma meta de crescimen- 
to tão ambiciosa, os empregados do banco começaram a ter um comportamento muito arriscado, aceitando emprestar dinheiro para clientes não tão seguros, comprando carteiras de crédito de bancos menores que realizavam operações bastante arriscadas, entre outras operações de alto risco. Caso os empréstimos tivessem sido pagos, o Continental Illinois BanK teria alcançado seu objetivo de crescimento, entretanto, o que aconteceu, em decorrência da falta de pagamento, foi um processo de crise financeira no banco, que levou o governo a socorrê-lo para que não quebrasse.

Outra consequência das metas muito desafiadoras são os custos psicológicos advindos da situação de estresse que é gerada no momento da execução de uma tarefa que está atrelada a uma meta. Segundo Ordóñez et al.(2009), quando essa meta é muito desafiadora e não é atingida, os empregados tendem a ter uma queda da percepção de sua eficácia, trazendo consigo custos psicológicos que podem levar a uma diminuição do comprometimento e do esforço na realização das suas atividades.

Nota-se que as metas desafiadoras nem sempre são sinônimas de maiores resultados, apesar da teoria das metas e seus defensores advogarem que sim. A seguir, será apresentada a relação entre metas e aprendizado.

\subsection{Manipulação dos Meios para o Alcance de Metas}

A manipulação ou adequação dos meios para atingir metas foi objeto de estudo de Hood (2006), ele realizou uma pesquisa com pessoas do governo da Inglaterra próximas ao antigo primeiro ministro Tony Blair, durante seu mandato. Ele também pesquisou documentos do governo para a consecução do seu trabalho. O governo de Tony Blair foi objeto de estudo, pois ele introduziu uma grande sistemática de metas para a gestão da máquina pública. Essas metas iam desde o alto escalão até as esferas mais baixas e levaram a dados surpreendentes, como a redução do número de pacientes que esperavam por uma cirurgia por mais de 12 meses nos hospitais públicos, passando de 40.000, em 2001, para 10.000, em 2003. Todavia, como esses números eram fantásticos, o autor tentou identificar se aconteciam manipulações/deturpações da realidade por parte dos servidores públicos, para o alcance das metas.

Hood (2006), por meio da sua pesquisa, verificou que os servidores públicos ingleses utilizavam três tipos de manipulação da realidade, que o 
autor denominou de: efeito roquete, efeito limite e efeito acertando o alvo e errando o ponto.

O efeito roquete acontecia quando a meta utilizada por uma instituição inglesa possuía uma fórmula fixa de ajuste, ou seja, ela era aumentada anualmente a uma taxa fixa. Os servidores, sabendo disso, produziam o suficiente para alcançar a meta no ano, não atingindo assim seu potencial de desempenho. Nota-se que, nesse caso, os servidores poderiam produzir mais do que a meta exigia, mas como não possuíam incentivos para tanto, declinaram sua própria produtividade.

O efeito limite foi observado quando o governo delimitava uma única meta para diversas instituições. Essa atitude fazia com que as instituições que alcançavam os melhores resultados diminuíssem a qualidade ou a quantidade do seu produto/serviço até o limite requerido pela meta.

O efeito acertando o alvo e errando o ponto foi identificado quando os servidores utilizavam artimanhas para o alcance das metas, sem se importar com as consequências dos seus atos. Pode-se citar, como exemplo, a atitude dos servidores públicos da área da saúde, que, para baterem sua meta de tempo de espera de atendimento nos hospitais, mantinham pacientes dentro das ambulâncias até terem condições de atendê-los.

Hood (2006) afirmou, no seu trabalho, que há evidências concretas de todos esses comportamentos, inclusive pareceres da auditoria pública inglesa corroborando suas descobertas. Percebe-se que essas atitudes dos servidores foram motivadas por um sistema de metas, que gerou perda de desempenho e até comportamentos não éticos no governo inglês.

Behn (2007) também identificou algumas manipulações da realidade para o alcance de metas. Ele percebeu que a utilização de poucas medidas para se verificar o desempenho de uma organização pode ser um grande erro. Esse foco em poucos indicadores concentra a atenção dos empregados, levando-os a não avaliarem as outras dimensões da organização, conforme Ordóñez et al. (2009) observaram em relação às metas muito específicas citadas no subitem 3.1. Dessa forma, os empregados fazem tudo o que é possível para que as metas desses poucos indicadores sejam alcançadas, independente das consequências desses atos. O autor cita como exemplo o comportamento de algumas escolas americanas. Conforme a política educacional dos Estados Unidos, essas escolas são avaliadas anualmente por meio de uma prova aplicada aos alunos. Essa prova, todavia, não abrange todas as disciplinas que são ministradas. Visando aumentar a sua nota, algumas esco- 
las estavam cortando da sua grade de ensino algumas matérias que não são exigidas na prova, focando toda a atenção naquelas que são cobradas. Tal adaptação dos meios para se alcançar uma meta pode trazer sérias consequências negativas para a formação dos alunos.

Observou-se que as metas podem influenciar o comportamento das pessoas, fazendo com que elas busquem alternativas cada vez mais confortáveis para o alcance das suas metas, mesmo que essas atitudes não maximizem os resultados da organização.

\subsection{Metas como Limitadoras do Aprendizado}

As organizações precisam de empregados capazes de aprender e colaborar com os demais, trabalhando em equipe e criando sinergias, entretanto, a utilização de metas pode ser um fator inibidor tanto do aprendizado quanto da cooperação entre pares e setores (ORDÓÑEZ et al., 2009).

A importância do aprendizado para o desenvolvimento de uma atividade foi exposta por Seijts e Latham (2005). Em diversas situações, antes de se focar diretamente o alcance de metas de desempenho, é necessário adquirir os conhecimentos básicos sobre a atividade para, posteriormente, procurar alcançá-las.

As metas podem ser um fator inibidor do aprendizado, na medida em que elas fazem com que o empregado tenha um foco excessivo em seu alcance e, assim, não consiga buscar um aprendizado sobre a tarefa por meio de uma análise crítica do processo. Caso ele não estivesse sob a sombra de uma meta, provavelmente, conseguiria analisar outras variáveis inerentes à tarefa, examinar criticamente o processo e, com a experiência adquirida, desenvolver melhorias para o aumento da produtividade organizacional (ORDÓÑEZ et al., 2009).

Fried e Slowik (2004) estudaram o fator tempo na teoria das metas e afirmaram que, para se ter desempenho, o prazo deve ser suficiente para o alcance da meta. Por outro lado, esse tempo pode se tornar um fator de desmotivação e diminuir os resultados de uma empresa, caso ele não seja bem calculado. Se a organização definir um tempo muito longo para o alcance de uma meta, o empregado pode diminuir a produtividade para a consecução da sua atividade. Se o tempo definido for muito curto, o empregado pode perceber que não irá conseguir realizar sua tarefa e se desmotivar, reduzindo, da mesma forma, a sua produtividade. 
Seijts e Latham (2005) ressaltaram um equívoco realizado por diversas empresas, já que elas definem suas metas de desempenho, cobram resultados das pessoas, mas não verificam se as competências necessárias para a realização da tarefa estão dominadas pelos empregados. Essa prática tende a não gerar os resultados esperados e promove desmotivação da força de trabalho. Nesse sentido, antes de se cobrar metas de resultado, deve-se utilizar metas de aprendizado, visando dar um arcabouço de habilidades e conhecimentos necessários para os empregados executarem bem suas tarefas. $\mathrm{Na}$ teoria, essas metas de aprendizado motivam a equipe na busca de conhecimentos para o desempenho de suas funções.

Em outras palavras, as metas podem exigir toda a concentração das pessoas, em detrimento de coisas que se revelarão necessárias no futuro das organizações. As pessoas que possuem um prazo apertado para o alcance de uma meta geralmente não possuem tempo para discutir uma melhor forma de realizar as tarefas. Nota-se que, dessa forma, não se promove o aprendizado e se debilita a organização no que se refere à inovação.

Verifica-se, então, que as metas podem ser um grande obstáculo para a promoção do aprendizado organizacional.

Na sequência, será analisada a relação entre metas e ética nas organizações.

\subsection{Metas e Comportamentos não Éticos}

Barsky (2007) desenvolveu o modelo apresentado na Figura 1, que mostra a conexão entre um sistema de metas e comportamentos não éticos. 


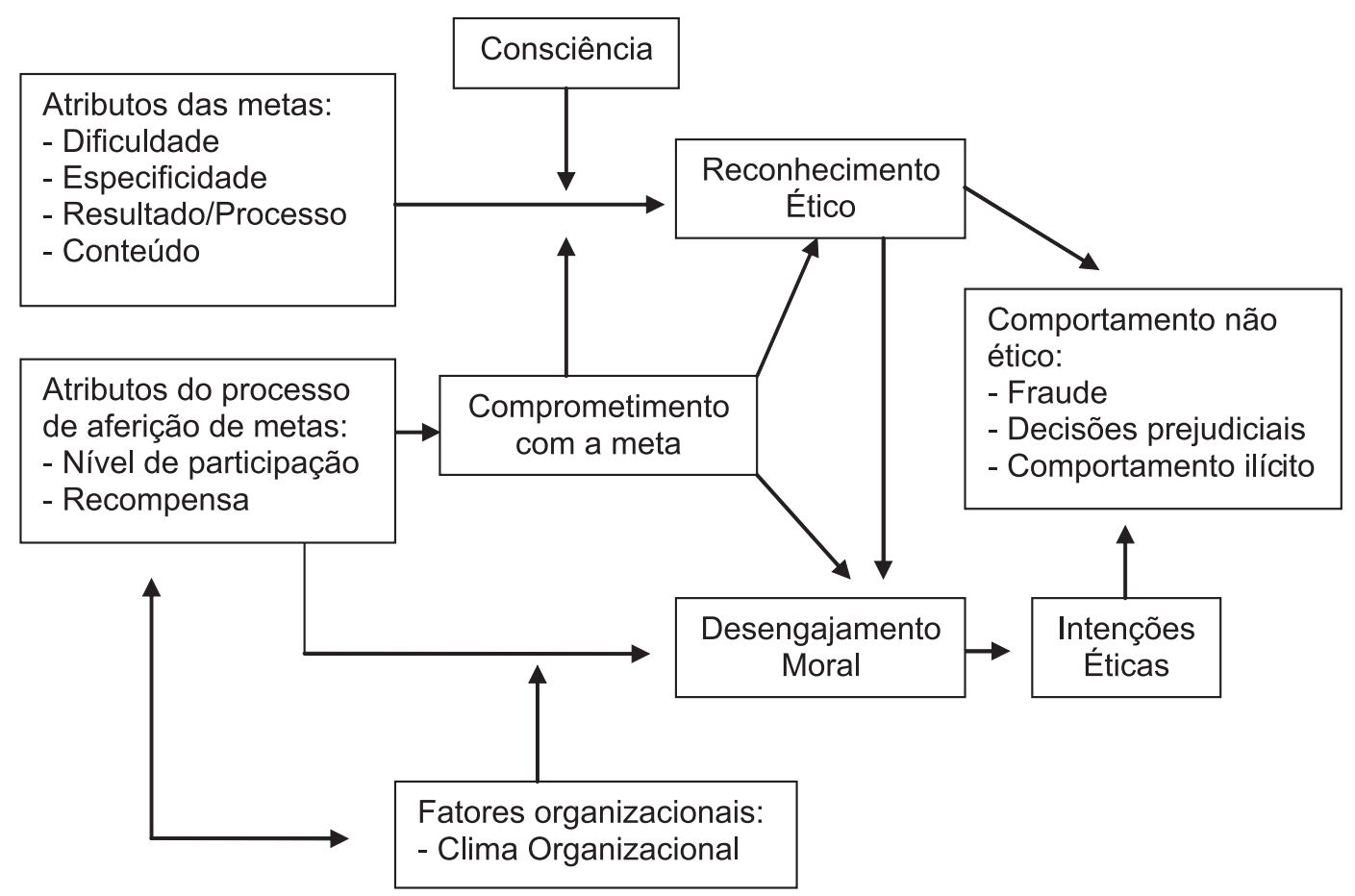

Figura 1: Sistema de metas e comportamento não ético Fonte: Barsky (2007, p. 64)

O modelo em questão deve ser analisado da esquerda para a direita, partindo dos atributos e do processo de aferição das metas. Nota-se que as metas influenciam o psicológico das pessoas, afetando assim suas atitudes. A consciência e o comprometimento com a meta fazem o principal link com o comportamento não ético, porém o autor considera que o processo de aferição de metas pode, por si só, gerar um desengajamento moral. O clima organizacional pode gerar, também, o comportamento não ético, na medida em que influencia o processo de aferição de metas e o desengajamento moral.

Esse modelo foca em dois processos psicológicos principais: o reconhecimento de uma questão ética e os controles internos para se atuar de forma ética. Barsky (2007) argumenta que a busca das pessoas pelo alcance de metas interfere no reconhecimento de questões éticas.

Segundo Barsky (2007), o comportamento não ético para se atingir uma meta não é devido a uma característica inerente ao indivíduo, de fazer o que 
não é correto, mas sim uma consequência de um sistema de metas estipulado pela organização.

Segundo o modelo de tomada de decisões éticas simplificado, de Choi (2010), o indivíduo passa por quatro fases antes de tomar uma decisão, a saber: dilema ético, percepção do problema ético, sensibilidade ética e razão ética.

O dilema ético diz respeito à decisão de se realizar ou não alguma ação que tenha implicações éticas. A percepção do problema ético é a principal fase desse modelo, pois, se o indivíduo não tiver consciência da dimensão não ética da decisão que irá tomar, o problema ético passará a não existir para ele e a decisão se tornará uma decisão qualquer. A sensibilidade ética refere-se à intensidade e ao impacto da ação, e a razão ética refere-se a uma análise racional da ação. Nesse sentido, a decisão pelo comportamento não ético em relação às metas deve passar pela consciência que o indivíduo possui sobre a ação, se ele tem ou não noção daquilo que está fazendo.

Schweitzer, Ordóñez e Douma (2004) realizaram um experimento com estudantes de graduação para investigar hipóteses a respeito da relação entre utilização de metas e comportamentos não éticos. Os autores utilizaram como premissa básica a ideia de que as pessoas tomam decisões ponderando os custos e os benefícios de se proceder a um comportamento não ético para o alcance de metas. Seguindo essa linha de pensamento, as pessoas incorrem em custos psicológicos ao admitirem que não cumprirão uma meta e, de maneira análoga, elas incorrem em recompensas psicológicas ao conseguirem, ou afirmarem que conseguiram, atingir uma meta. Foram estudadas as três hipóteses relacionadas a seguir:

a) Hipótese 1: pessoas com metas específicas e não atingidas são mais propensas a fraudar seu desempenho do que pessoas sem metas específicas, ou seja, pessoas que apenas tentam fazer o melhor possível, sem uma meta.

b) Hipótese 2: pessoas com metas atreladas à recompensa, quando não as atingem, estarão mais propensas a fraudar seu desempenho do que pessoas com metas não atreladas a recompensas.

c) Hipótese 3: pessoas que falharam ao atingir uma meta por uma pequena margem estarão mais propensas a falsamente clamarem ter alcançado suas metas do que pessoas que falharam ao atingir uma meta por uma larga margem. 
Os autores acreditavam, a partir da Hipótese 1, que os empregados em organizações que não possuíam uma meta de desempenho utilizavam menos métodos não éticos do que aqueles com metas de desempenho específicas e bem definidas.

A Hipótese 2 investigou a meta atrelada à recompensa como um fator que leva as pessoas a comportamentos não éticos. Esperava-se que os empregados que trabalhassem com metas atreladas às recompensas estariam mais propensos a comportamentos não éticos do que alguém com metas simples, não atreladas a premiações.

A Hipótese 3 evidenciou a distância do alcance da meta como um fator propulsor do comportamento não ético. Esperava-se, todavia, que os empregados das diversas organizações, quando não alcançassem suas metas por uma pequena margem, incorressem em comportamentos não éticos com uma maior frequência do que aqueles que não alcançassem a meta por uma grande margem.

O resultado da pesquisa evidenciou que as Hipóteses 1 e 3 foram comprovadas, sendo que os dados estatísticos não deram suporte para a hipótese 2. Constatou-se, então, que empregados com metas específicas e não atingidas são mais propensos a fraudar seu desempenho do que aqueles sem metas específicas. Concluiu-se também que empregados que falharam ao atingir uma meta por uma pequena margem estão mais propensos a, falsamente, afirmar ter alcançado suas metas do que aqueles que falharam ao atingi-las por uma larga margem. Concluiu-se, ainda, que se deve ter cuidado ao utilizar metas como uma ferramenta de gestão, pois pode ser algo danoso para a consecução das estratégias das organizações (SCHWEITZER; ORDÓÑEZ; DOUMA, 2004).

Observa-se que a utilização de metas pode induzir as pessoas a cometer atos não éticos, inclusive ilícitos. A motivação das pessoas para tal comportamento está associada à busca do alcance das metas, conforme evidenciado neste item. Em seguida, será analisada a relação entre metas e motivação no setor público.

\subsection{As Metas e o Comportamento em Organizações Públicas}

Segundo Houston (2009), o local de trabalho e o tipo de atividade geram um alto grau de impacto em quem trabalha no setor público, pois a própria atividade é um dos principais fatores intrínsecos de motivação. Nesse 
sentido, um sistema de metas na administração pública, que é um fator extrínseco, se não estiver alinhado com fatores intrínsecos motivacionais, podem não gerar os resultados esperados.

Paine (2009) mostrou que a motivação no serviço público não é explicada estatisticamente, de forma contundente, pelas variáveis: recompensa material, trabalho no serviço público por si só e pela tarefa realizada.

Outras questões que afetam o desempenho de quem trabalham sob o regime de metas são a resistência das pessoas e o papel da gerência. Tal situação foi observada no âmbito de alguns órgãos na fase inicial do Acordo de Resultados do Estado de Minas Gerais. Segundo Carneiro e Barbosa (2007), o acordo de resultados implantado pelo governo, que consistiu em utilizar um sistema de metas atrelado a uma recompensa, teve poucas adesões na sua fase inicial. Como as próprias Secretarias de Estado não aderiram, em sua totalidade, a essa estratégia, porque as metas, em um primeiro momento, não motivaram as pessoas no serviço público, foi adotada uma ação mais enérgica para uma maior participação. O referido comportamento encontra respaldo nos estudos de Avakian (2009), que evidenciaram a existência de uma grande resistência, por parte dos empregados das organizações, em alcançar metas. Foi observado que o caminho utilizado por algumas empresas tem sido enfrentar as resistências por meio da força. O autor sugere que o enfrentamento da resistência por meio da força é o melhor caminho para a consecução da estratégia. Todavia, é razoável supor que o uso constante da força, por parte da organização, visando o alcance das metas estratégicas, não seja uma opção que possa perpetuar no tempo sem consequências negativas.

Outra questão importante que foi tratada por Paiva e Couto (2008) é o estresse gerencial gerado a partir da introdução de um sistema de medição atrelado à recompensa, como foi o caso da Companhia de Saneamento de Minas Gerais - Copasa. Notou-se que o processo de introdução de um sistema de metas gerou uma grande resistência por parte dos empregados e da própria gerência.

O uso das metas no serviço público sofre limitações específicas em decorrência da motivação intrínseca peculiar às pessoas e das contingências organizacionais. Muitas vezes, as características do ambiente organizacional público são relevantes o bastante para alterar significativamente as chances de sucesso e de melhoria no desempenho. 


\section{Considerações Finais}

A teoria das metas, segundo Locke e Latham (1990; 1996), evidencia a importância de um sistema de metas para aumentar o desempenho organizacional. Esses autores mostraram que as metas devem ser desafiadoras, específicas e atingíveis. Muitos outros autores comprovaram e complementaram essa teoria. Da mesma forma, muitos executivos tiveram sucesso com o seu uso, entretanto, Ordóñez et al. (2009) afirmam que a utilização de um sistema de medição e aferição de metas não é algo simples e que não leva, necessariamente, a empresa a melhores resultados. Essa constatação evidencia que a utilização de metas de resultado não é suficiente para que uma empresa tenha um desempenho superior.

Este artigo teve como principal limite a não utilização de pesquisa de campo para se comprovar empiricamente a hipótese de que um sistema de metas não é condição suficiente para se ter desempenho organizacional.

Entretanto, este estudo buscou uma abrangente revisão da literatura sobre o tema, abrindo espaço para pesquisas acadêmicas futuras. Existe também terreno para pesquisas específicas sobre esse assunto, principalmente com o advento de organizações públicas que utilizam sistemas de metas atrelados a recompensas, conforme mostrado por Carneiro e Barbosa (2007), no Governo do Estado de Minas Gerais. Outro tema emergente refere-se a entender a percepção das pessoas sobre as metas e, a partir do que for constatado, analisar sua produtividade. Entende-se que é bem provável que haja pessoas que não gostam de trabalhar com metas e isso pode refletir na produtividade.

\section{The Goal-Setting Systems Limitations}

\section{Abstract}

In this environment of great uncertainty where the organizations are included, the correct use of a measuring system might mean competitive advantage and performance. This essay seeks to clarify the limits of measurement systems, verifying whether the use of outcome goals is enough to boost superior performance to a company. The objective is to analyze the theory of goals under a critical eye, noting 
the limits of the use of different types of goals, including in the public administration. We tried to make an analysis of the authors who advocate the use of goals to have performance and from the assumptions of these authors, analyzing the critics, showing that, in their view, they can cause, depending on the situation, serious financial and image damage for the organization. After this analysis, it was found that the goals have an important role to increase the performance of the organization, however, they must be use carefully, because they can lead people to unethical behavior, inhibiting cooperation and organizational learning, among others.

Key words: Goals. Goal-setting theory. Limits of the goal-setting theory. Measurement systems.

\section{Referências}

AVAKIAN, Paul N. Goal-obstacle conflicts. Business strategy series, Bingley, v. 10, n. 5, p. 287-295, 2009.

BARSKY, Adam. Understanding the ethical cost of organizational goal-setting: a review and theory development. Academy of management proceedings, Briarcliff Manor, p. 1-6, 2007. Disponível em: < http://web.ebscohost.com/ehost/ pdf?vid $=5 \&$ hid $=106 \&$ sid $=b 71 \mathrm{~d} 8 \mathrm{~b} 24-4586-4 \mathrm{c} 86-9 \mathrm{a} 8 \mathrm{f}-$ c18927fbb5b@sessionmgr112>. Acesso em: 18 mar. 2010.

BEHN, Robert. Danger of using too few measures. Bob Behn's public management report, Cambridge, v. 5, n. 2, oct. 2007. Disponível em: <http:// www.hks.harvard.edu/thebehnreport/October2007.pdf $>$. Acesso em: 5 jun. 2010.

BOYNE, George A.; CHEN, Alex A. Performance Targets and Public Service Improvement. Journal of public administration research and theory, Oxford, v. 17, n. 3, p. 455-477, 2007.

CARNEIRO, Ricardo; BARBOSA, Lúcio Otávio Seixas. Acordo de resultados: análise da experiência do governo mineiro. In: ENCONTRO NACIONAL DA ASSOCIAÇÃO DE PÓS-GRADUAÇÃO E PESQUISA EM ADMINISTRAÇÃO, 31., 2007, Rio de Janeiro. Anais... Rio de Janeiro: ANPAD, 2007. 
CHOI, do Lim; PERRY, James L. Developing a tool to measure ethical sensitivity in public administration and its application. International review of public administration, Seoul, v. 14, n. 3, p. 1-12, 2010. Disponível em: $<$ www.kapa21.or.kr/data/data _download.php?did=4142>. Acesso em: 14 ago. 2010.

CHU, K. Firms report lackluster results from pay-for-performance plans. Wall street journal, New York, p. 1, 15 jun. 2004. Caderno D.

CHUA, Fang-Fang; LEE, Chien-Sing. The effects of learning goals and modelling on virtual collaboration: a case study on the Merlin agent-assisted collaborative concept map. International Journal of Web Based

Communities, Enschede, v. 3, n. 2, p. 229-248, 2007. Disponível em: < http:// www.inderscience.com/search/ index.php?action=basic $>$. Acesso em: 18 set. 2010.

FRIED, Yitzhak; SLOWIK, Linda Haynes. Enriching goal-setting theory with time: an integrated approach. Academy of management review, Briarcliff Manor, v. 29, n. 3, p. 404-422, jul. 2004. Disponível em: <http:// web.ebscohost.com/ehost/pdf? vid=4\&hid $=3 \&$ sid $=28 \mathrm{f} 5 \mathrm{a} 740-\mathrm{ff0}-469 \mathrm{f}-8 \mathrm{~d} 45$ 9d28f216f263\%40sessionmgr10 >. Acesso em: 25 mar. 2010.

GEORGE, Michael S. Planning for success: setting goals. Officer review magazine, Alexander, v. 45, n. 10, p. 22-22, jun. 2006. Disponível em: <http:// web.ebscohost.com/ehost/pdf?vid=15\&hid =3\&sid =28f5a740-ff04-469f-8d459d28f216f 263\%40ses sionmgr10>. Acesso em: 25 mar. 2010.

HITT, Michael A.; IRELAND, R. Duane; HOSKISSON, Robert E.

Administração estratégica. Tradução de Eliane Kanner e Maria Emília Gutilla. 2. ed. São Paulo: Thomson Learning, 2008. 415 p.

HOOD, Christopher. Gaming in the targetworld: the targets approach to managing british public services. Public administration review, Malden, $v$. 66, n. 4, p. 515-521, jul./aug. 2006. Disponível em: <http://web.ebscohost.com/ ehost/pdfviewer $/$ pfviewer?vid $=5 \&$ hid $=112 \&$ sid $=356 \mathrm{cc} 1$ e8-7689-42e1-90fd96073ca6dc0\%40sessio nmgr110>. Acesso em: 5 maio 2010.

HOUSTON, David J. The importance of intrinsic and extrinsic motivators: examining attitudes of government workers in North America and Western Europe. In: INTERNATIONAL PUBLIC SERVICE MOTIVATION RESEARCH CONFERENCE, 2009, Bloomington. Anais... Bloomington: IPSM, 2009. 
KAPLAN, Robert S.; NORTON, David P. A estratégia em ação: balanced scorecard. Tradução de Luiz Euclydes Trindade Frazão Filho. 3. ed. Rio de Janeiro: Campus, 1997. 344 p.

KAPLAN, Robert S.; NORTON, David P.. Mapas estratégicos: convertendo ativos intangíveis em resultados tangíveis. Tradução de Afonso Celso da Cunha Serra. 9. ed. Rio de Janeiro: Campus, 2004. 471 p.

\section{LOCKE, E. A.; LATHAM, G. P. A theory of goal setting and task} performance. Englewood Cliffs: Prentice Hall, 1990.

LOCKE, E. A. Linking goals to monetary incentive. Academy of management executive, Birmingham, v. 18, n. 4, p. 130-133, nov. 2004. Disponível em: <http://web.ebscohost.com /ehost/ pdf?vid $=17 \&$ hid $=3 \&$ sid $=28 f 5 a 740-f f 04-469 f-8 d 45$ 9d28f216f263\%40sessionmgr10>. Acesso em: 25 mar. 2010.

LOCKE, Edwin A.; LATHAM, Gary P. New directions in goal-setting theory. Association for psychological science, Washington, v. 15, n. 5, p. 265268, 2006. Disponível em: <http://web.ebscohost.com/ehost/ pdf?vid = 16\&hid =3\&sid = 28f5a740-ff04-469f-8d45-9d28f21 6f263\%40sessionmgr10 >. Acesso em: 25 mar. 2010.

MEDLIN, Bobby; GREEN JR, Kenneth W. Enhancing performance through goal setting, engagement, and optimis. Industrial Management \& Data Systems, Bingley, v. 109, n. 7, p. 943-956, 2009.

ORDÓÑEZ, Lisa D. et al. Goals gone wild: the systematic side effects of overprescribing goal setting. Academy of management perspectives, Birmingham, v. 23, n. 1, p. 6-16, feb. 2009. Disponível em: <http:// web.ebscohost.com/ehost/pdf?vid =18\&hid=3\&sid=28f5a740-ff04-469f-8d459d28f21 6f263\%40sessionmgr10>. Acesso em: 25 mar. 2010.

PAINE, Jeffrey R. Motivation to serve the public: testing the measures and exploring the antecedents in local government. In: INTERNATIONAL PUBLIC SERVICE MOTIVATION RESEARCH CONFERENCE, 2009, Bloomington. Anais... Bloomington: IPSM, 2009.

PAIVA, Kely César Martins de; COUTO, João Henrique. Qualidade de vida e estresse gerencial "pós-choque de gestão": o caso da Copasa-MG. Revista de administração pública, Rio de Janeiro, v. 42, n. 6, p. 1189-1211, nov./dez. 2008. 
SCHWEITZER, Maurice E.; ORDÓÑEZ, Lisa; DOUMA, Bambi. Goal setting as a motivator of unethical behavior. Academy of management journal, Danvers, v. 47, n. 3, p. 422-432, jun. 2004. Disponível em: <http:// web.ebscohost.com/ehost/pdf ?vid=19\&hid=3\&sid= 28f5a740-ff04-469f-8d459d28f216f263\%40sessionmgr10>. Acesso em: 25 mar. 2010.

SEIJTS, G. H.; LATHAM, G. P. Learning versus performance goals: when should each be used? Academy of management executive, Birmingham, $v$. 19, n. 1, p. 124-131, feb. 2005. Disponível em: <http://web.ebscohost.com/ ehost $/$ pdf?vid $=20 \&$ hid $=3 \&$ sid $=28 f 5 a 740-f f 04-469 f-8 d 45$ 9d28f216f263\%40sessionmgr10>. Acesso em: 25 mar. 2010.

SIMON, Robert. Performance measurement and control systems for implementing strategy. New Jersey: Prentice-Hall, 2000. 780 p.

TOSI, Henry L. Theory of goal setting and task performance (book review). Academy of management review, Briarcliff Manor, v. 16 n. 2, p. 480-483, apr. 1991. Disponível em: <http://web.ebscohost.com/ehost/ pdf?vid $=21 \&$ hid $=3 \&$ sid $=28 f 5 a 740-f f 04-469 f-8 d 45-9 d 28 f$ 216f263\%40sessionmgr10>. Acesso em: 25 mar. 2010.

YEARTA, Shawn K.; MAITLIS, Sally; BRINER, Rob B. An exploratory study of goal setting in theory and practice: a motivational technique that works.

Journal of occupational and organizational psychology, Leicester, v. 68, n. 3, p. 237-252, sep. 1995. Disponível em: <http://web.ebscohost.com/ehost/ pdfviewer/pdfviewer?vid $=17 \&$ hid $=103 \&$ sid $=424 \mathrm{c} 6 e \mathrm{e} 4$-cde6-42dc-9d8a19d5d02b3eba\%40sessionmgr111>. Acesso em: 6 abr. 2010.

ZANINI, Marco Tulio F.; LUSK, Edward J.; WOLFF, Birgitta. Confiança dentro das organizações da nova economia: uma análise empírica sobre as consequências da incerteza institucional. Revista de administração contemporânea, Curitiba, v. 13, n. 1, p. 72-91, jan./mar. 2009. Disponível em: $<$ http://www.scielo.br/pdf/rac/v13n1/a0 6v13n1.pdf>. Acesso em: 9 mar. 2010. 